\title{
Bioprospective Screening of Antibacterial and Phytochemical Activity of Caesalpinia Pulcherrima (Pride of Barbados) on Selected Clinical Isolate
}

\section{OludareTemitope Osuntokun ${ }^{1 *}$, Julianah JU2 ${ }^{2}$ and Thonda $\mathrm{OA}^{3}$}

${ }^{1}$ Department of Microbiology, Adekunle Ajasin University, Nigeria

${ }^{2}$ Department of Microbiology, Adekunle Ajasin University, Nigeria

${ }^{3}$ Department of Biological Science, Kings University, Nigeria

\section{Research Article \\ Volume 1 Issue 3}

Received Date: November 02, 2017

Published Date: December 29, 2017

*Corresponding author: Oludaretemitope Osuntokun, Department of Microbiology, Faculty of Science, Adekunle Ajasin University, Akungba Akoko, PMB 001, Ondo State, Nigeria, Tel: 8063813635; E-mail: osuntokun4m@yahoo.com

\section{Abstract}

This research work was carried out to evaluate the antibacterial and Phytochemical activities of Caesalpiniapulcherrima leaf and stem bark on some clinical isolates. The plant parts were collected from St. Benedict Catholic Church premises, Owena Barracks, Akure, Ondo State. Crude ethyl acetate extracts of Caesalpinia pulcherrima leaves and stem bark was assayed for its antibacterial activity against Staphylococcus aureus, Klebsiella pneumonia, Pseudomonas aeruginosa, Bacillus subtilis, Escherichia coli, and Salmonella typhi. using agar well diffusion method. Ofloxacin was used as standard control. The ethyl acetate extract of Caesalpiniapulcherrima leaves inhibited the growth of Escherichia coli, Staphylococcus aureus, and Salmonellatyphi with $12 \mathrm{~mm}, 10 \mathrm{~mm}$ and $12 \mathrm{~mm}$ zone of inhibition at $100 \mathrm{mg} / \mathrm{ml}$ concentration and $4 \mathrm{~mm}, 4 \mathrm{~mm}$ and $6 \mathrm{~mm}$ zone of inhibition at $12.5 \mathrm{mg} / \mathrm{ml}$ concentration respectively but ineffective against Klebsiella pneumonia and Pseudomonas aeruginosa. It also inhibits the growth of Bacillus substilis with $7 \mathrm{~mm}$ zone of inhibition at $100 \mathrm{mg} / \mathrm{ml}$ concentration and $3.0 \mathrm{~mm}$ zone of inhibition at $25 \mathrm{mg} / \mathrm{ml}$ concentration.

The ethyl acetate extract of the stem bark inhibited the growth of Escherichiacoli, with $12 \mathrm{~mm}$ and $4 \mathrm{~mm}$ zone of inhibition at $100 \mathrm{mg} / \mathrm{ml}$ and $25 \mathrm{mg} / \mathrm{ml}$ concentration and Staphylococcus and Salmonellatyphi with $10 \mathrm{~mm}$ and $15 \mathrm{~mm}$ inhibition zones at $100 \mathrm{mg} / \mathrm{ml}$ concentration and $4 \mathrm{~mm}$ and $4 \mathrm{~mm}$ zone of inhibition at $12.5 \mathrm{mg} / \mathrm{ml}$ respectively, but were ineffective against other isolates. Both qualitative and quantitative phytochemical evaluations were also carried out on both the leaves and stem bark of Caesalpinia pulcherrima and results revealed the presence of several phytoconstituents such as alkaloids, cardiac glycoside, steroids, anthraquinones, phenols, tannins, saponins, flavonoids and reducing sugar with the bark possessing more of the phytochemicals. It has been reported in the literature that these species exhibit a wide range 


\section{Bioequivalence \& Bioavailability International Journal}

of pharmacological properties, including antiulcer, anticancer, anti-diabetic, anti-inflammatory, antimicrobial, and antirheumatic activities that have proven to be efficacious in ethno-medicinal practices. This work is aimed at; investigating the antibacterial and phytochemical activity of Caesalpinia pulcherrima against selected bacteria species.

Keywords: Caesalpinia pulcherrima leaf; Stem bark Antibacterial; Phytochemical activity

\section{Introduction}

Caesalpinia pulchirrima (Fabaceae) is native to tropics and subtropics area of the Americas. This plant is widely distributed in Bangladesh and India. It is a common medicinal plant in India, Taiwan and south East Asian and African countries [1].

Caesalpinia pulchirrima is a striking ornamental plant, widely grown in domestic and public gardens and has a beautiful inflorescence in yellow, red and orange. Caesalpinia pulchirrima species is ash rub growing to $3 \mathrm{~m}$ tall. The leaves are bi pinnate, $20-40 \mathrm{~cm}$ long, bearing 310 pairs of pinnae, each with 6-10 pairs of leaflets 15 $25 \mathrm{~mm}$ long and $10-15 \mathrm{~mm}$ broad. The flowers are borne in racemes up to $20 \mathrm{~cm}$ long, each flower with five yellow, orange or red petals. The fruit is a pod6-12 cm long. Flowers are red or yellow, fragrant. Flowering season of this plant start from September to November and fruits from March to April [2].

Its various parts have been used for cure of a number of disorders including pyrexia, menoxenia, wheezing, bronchitis, and malarial infection [3]. Traditionally leaves of Caesalpinia pulchirrimaare used as purgative, tonic, antipyretic, emmenagogue, whereas roots have folkloric use in convulsion, intermittent fever, lungs and skin diseases [4]. Flavonoids are polyphenolic compounds, widely distributed in the plant kingdom. They are reported to exhibit various pharmacological activities such as CNS, cardiotonic, lipid lowering, anti-oxidant, Hepato protective and hypoglycemic activities [5]. The Caesalpinia pulchirrima possesses various bioactive compounds such as steroid, reducing sugar, triterpenoids, sugar, alkaloids, phenolic compounds, flavonoids, catechins, saponins, tannins, anthraquinones and amino acid.

The leaves of the plant Caesalpinia pulchirrima are reported to contain hydrocyanic acid, tannins and benzoic acid. The plant contains various phyto active consituents such as glycosides, rotenids, is flavones, flavonone, chalcones, flavanols, flavones and sterols [1]. Root of Caesalpinia pulchirrima showed the presence of diterpenoids, isovouacapenol $\mathrm{C}$ and pulcherrimin $\mathrm{A}$. The stem contains peltogynoidsbhonducellin, 6methoxypulcherrimin and homomisoflavonoids. The flavonoids are polyphenolic compounds and reported to exhibit various pharmacological activities such as CNS activity, cardiotonic activity, lipid lowering activity, antioxidant activity, hepatoprotective activity, hypoglycemic activity and so on [5]. These active constituents and the above mention activities in turn appear to correlate with some other biological activities. Survey revealed that the different parts of Caesalpiniapulchirrima have been screened for various pharmacological activities but anti-diabetic and antioxidant activities were not investigated in Caesalpinia pulchirrima flowers (Figure 1).

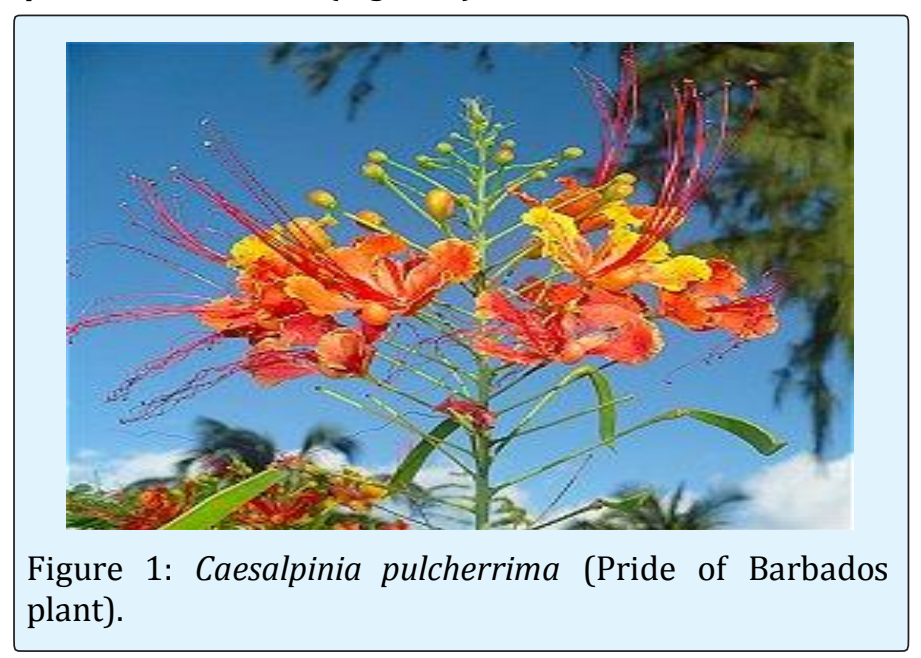

Caesalpinia pulcherrima also known as Pride of Barbados plant is a perennial large shrub or small tree found throughout the world. It has several medicinal properties, used in treatment of ulcer, fever, tumors, asthma, cholera, for abortion, promotes menstrual flow, as a purgative or the watery evacuation of the bowels, for producing energy, to relieve chest affections, widely used for the cure of bronchitis, for malarial fevers and so many others [3]. Ceasalpiniapulcherrima also has uses in the folk medicine: the stem is used as an abortifacient and emmenagogue, while decoctions of the roots and bark are used as a febrifuge and to treat liver disorders as well as ulcers from mouth and throat. Previous studies on this 


\section{Bioequivalence \& Bioavailability International Journal}

plant have resulted in the isolation of several diterpenoids [6,7], flavonoids, peltogynoids, and homomisoflavonoids. Some of the constituents were found to possess antitumor, antimicrobial properties. The infusion of the leaves or the bark is used to prevent recurrence like malaria, promote menstrual flow, and work as a purgative and for producing energy. Due to the presence of different chemical compounds, the bark part of this plant may possess some pharmacological activities.

A combination of the roots, bark, and leaves may be boiled into a medicinal tea, which is given to patients as a treatment for fever, jaundice, kidney disease, and gastrointestinal disorders. Gargling with the tea is also said to treat sores in the mouth or throat. Disorders from the respiratory system can be treated by giving the patients the seed of the plant to chew. The root also contains toxins that are sometimes used by folk doctors to induce abortion.

A liquid extracted from the flowers of the plant is often used topically as an eye wash or applied to the body as an insecticide. The liquid is sometimes consumed to treat a variety of other conditions. Patients with severe gastrointestinal disorders, including dysentery or severe diarrhea, may also be given the fruit of the plant, which is said to have astringent properties, to eat. These properties help the plant to dry out the intestinal tract. The plant is known, however, to be an antiseptic and an anti-inflammatory. These qualities may make it useful in the treatment of gastrointestinal disorders and internal or external wound.

Preliminary medical studies have also indicated that Caesalpiniapulcherrima may also assist in weight loss. Mice given enzymes that are found in this plant were able to lose weight at a faster rate than the mice in the control group. Despite its potential medicinal uses

\section{Materials and Methods}

\section{Plant Sample}

Collection, Source and Identification of Plant Materials: The leaves and barks of Caesalpinia pulcherrima were used for this study. The leaves and stem bark were collected in November 2016 from St. Benedict Catholic Church compound in 32 Artillery Regiment Owena Cantonment Army Barracks, Akure, Ondo State and were authenticated at the department of Plant Science and biotechnology, Adekunle Ajasin University, Akungba Akoko, Ondo State (Figure 2).

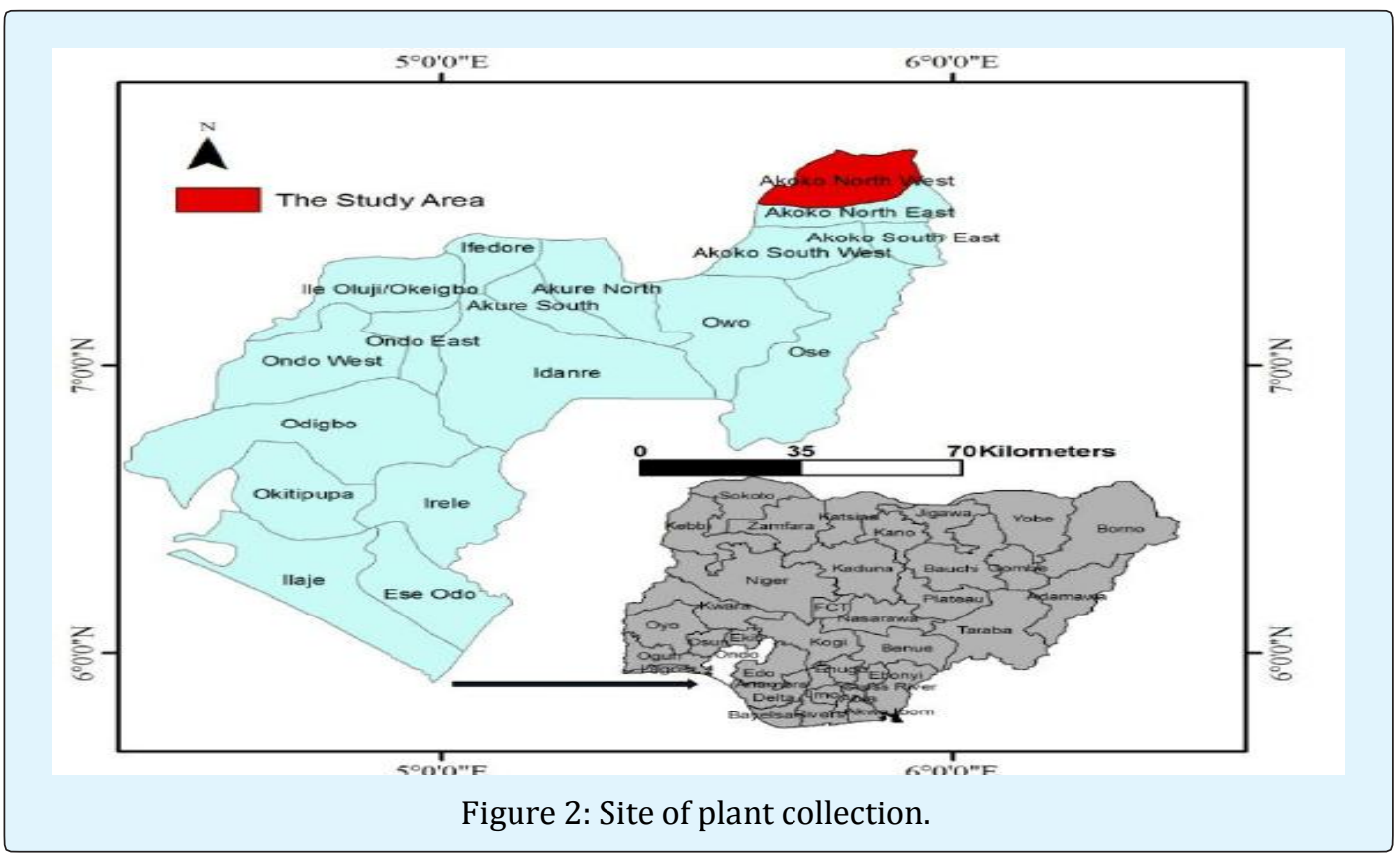

\section{Preparation of Plants Extract}

Caesapinia pulcherrima leaves and barks were rinsed with clean water to remove dirt and other particles and were dried at room temperature for two weeks. The dried leaves and barks were crushed manually into powdered form with the help of a mortar and pestle. $300 \mathrm{~g}$ of each of the sample were soaked in $900 \mathrm{ml}$ of ethyl acetate for 7 days respectively. After which it was filtered with No1 what man filter paper. The extract was evaporated to 
dryness by rotary evaporator to get a viscous mass. The viscous mass was then poured into a glass petri dishes and air dried and weighed to get a dried extract. The extract was weighed to be $18 \mathrm{~g}$ for ethyl acetate extract of Caesalpinia pulcherrima bark 13g for ethyl acetate extract of Caesalpinia pulcherrima leaves. This extract was used for pharmacological screening. The extract was then prepared for each solvent extract by dissolving $1 \mathrm{~g}$ of extract in $2.5 \mathrm{ml}$ of DMSO and $7.5 \mathrm{ml}$ of distilled water [8].

\section{Extraction of Plant}

Rotary evaporator was used in the removal of solvent of extraction from the extracts. The boiling point of ethyl acetate is $77^{\circ} \mathrm{C}$ respectively, the set temperature was also set on the rotary evaporator for each solvent. After evaporation, the extract were poured into different Petri dishes and air dried.

\section{Test Organisms}

The sensitivity of the following bacteria to extracts of Caesalpiniapulcherrima was assayed: Staphylococcus aureus, Bacillus subtilis, Escherichia coli, Pseudomonas aeruginosa, Salmonella typhi, and Klebsiella pneumonia. These organisms were collected from the Microbiology laboratory of AdekunleAjasin University, Akungba Akoko, and Ondo state. The organisms were maintained by sub culturing onto nutrient agar slants and grown at $37^{\circ} \mathrm{C}$ for 24 hours and was kept in the refrigerator until when needed [8].

\section{Antibacterial Assay}

The extracts of the leaves and bark of Caesalpinia pulcherrima were tested for antibacterial activity against the test organisms employing the Agar well diffusion method [9].

The test bacterium was spread on the surface of the Mueller Hinton Agar plates and the plates were allowed to solidify. Wells were bored on the plates using a sterile cork borer of $6 \mathrm{~mm}$ diameter. A stock solution of 100 $\mathrm{mg} / \mathrm{ml}$ of each extract obtained by dissolving the extract in sterile distilled water, varying concentrations of the extracts were prepared to obtain 50,25 and $12.5 \mathrm{mg} / \mathrm{ml}$ of each extract. The wells were filled with $0.1 \mathrm{ml}$ of the extract containing different concentration and antibiotics (Ofloxacin) used for control were introduced into the wells. The plates containing the extract were left on the bench for 2hours to allow the extract diffuse into the agar before incubation of the plates at $37^{\circ} \mathrm{C}$ for $18-24$ hours. The positive control consisted of Ofloxacin, the standard antibacterial drug at concentration of $50 \mathrm{mg} / \mathrm{ml}$. After 24hours, the plates were examined for clear zones around the well indicating the antibacterial activity of the extract [8].

\section{Phytochemical Screening}

\section{Qualitative Phytochemical Analysis of Caesalpinia Pulcherrima}

Test for Reducing Sugars: One milliliter of the plant filtrate was mixed with Fehling $\mathrm{A}$ and Fehling $\mathrm{B}$ separately; a brown colour with Fehling $B$ and a green colour with Fehling A indicate the presence of reducing sugars.

\section{Test for Alkaloids}

TLC method 1: Solvent system: Chloroform: methanol: $25 \%$ ammonia (8:2:0.5). Spots can be detected after spraying with Dragendorff reagent. Orange spot shows is a positive result.

TLC method 2: Wet the powdered test samples with a half diluted $\mathrm{NH} 4 \mathrm{OH}$ and lixiviated with EtOAc for $24 \mathrm{hr}$ at room temperature. Separate the organic phase from the acidified filtrate and basify with $\mathrm{NH} 4 \mathrm{OH}$ (pH 11-12). Then extract it with chloroform (3X), condense by evaporation and use for chromatography. Separate the alkaloid spots using the solvent mixture chloroform and methanol $(15: 1)$. Spray the spots with Dragendorff's reagent. An orange spot show is a positive result [10].

\section{Test for Anthraquinone}

a) Borntrager's test Heat about $50 \mathrm{mg}$ of extract with $1 \mathrm{ml}$ $10 \%$ ferric chloride solution and $1 \mathrm{ml}$ of concentrated hydrochloric acid. Cool the extract and filter. Shake the filtrate with equal amount of diethyl ether. Further extract the ether extract with strong ammonia. Pink or deep red coloration of aqueous layer [11].

b) Borntrager's test Add $1 \mathrm{ml}$ of dilute (10\%) ammonia to $2 \mathrm{ml}$ of chloroform extract. A pink-red color in the ammoniacal (lower) layer [12].

\section{Test for Cardiac Glycosides}

Kellar- Kiliani test: Dissolve 50 mg of methanolic extract in $2 \mathrm{ml}$ of chloroform. Add H2SO4 to form a layer. Brown ring at interphase shows is a positive result [12].

TLC method: Extract the powdered test samples with $70 \% \mathrm{EtOH}$ on rotary shaker (180 thaws/min) for $10 \mathrm{hr}$. Add $70 \%$ lead acetate to the filtrate and centrifuge at $5000 \mathrm{rpm} / 10 \mathrm{~min}$. Further centrifuge the supernatant by adding $6.3 \% \mathrm{Na}_{2} \mathrm{CO}_{3}$ at $10000 \mathrm{rpm} / 10 \mathrm{~min}$. Dry the
OludareTemitope Osuntokun, et al. Bioprospective Screening of Antibacterial and Phytochemical Activity of Caesalpinia Pulcherrima (Pride of Barbados) on Selected Clinical Isolate. Bioequiv \& Bioavailab Int J 2017, 1(3): 000118.
Copyright@ OludareTemitope Osuntokun, et al. 


\section{Bioequivalence \& Bioavailability International Journal}

retained supernatant and re-dissolved in chloroform and use for chromatography. Separate the glycosides using EtOAc-MeOH-H2O (80:10:10) solvent mixture. The color and hRf values of these spots can be recorded under ultraviolet (UV254 nm) light [10].

\section{Test for Flavonoid}

Shinoda test: To $2-3 \mathrm{ml}$ of methanolic extract, add a piece of magnesium ribbon and $1 \mathrm{ml}$ of concentrated hydrochloric acid. Pink red or red coloration of the solution, shows is a positive result [11].

TLC method: Extract $1 \mathrm{~g}$ powdered test samples with $10 \mathrm{ml}$ methanol on water bath $\left(60^{\circ} \mathrm{C} / 5 \mathrm{~min}\right)$. Condense the filtrate by evaporation, and add a mixture of water and EtOAc (10:1 m L), and mix thoroughly. Retain the EtOAc phase and use for chromatography. Separate the flavonoid spots using chloroform and methanol (19:1) solvent mixture. The color and hRf values of these spots can be recorded under ultraviolet (UV254nm) light [10].

\section{Test for Phenol}

Phenol test Spot the extract on a filter paper. Add a drop of phosphomolybdic acid reagent and expose to ammonia vapors. Blue coloration of the spot, shows is a positive result [11].

\section{Test for Saponin}

Frothing test / Foam test: Add $0.5 \mathrm{ml}$ of filtrate with $5 \mathrm{ml}$ of distilled water and shake well. Persistence of frothing shows is a positive result [13].

TLC method: Extract two grams of powdered test samples with $10 \mathrm{ml} 70 \% \mathrm{EtOH}$ by refluxing for $10 \mathrm{~min}$. condense the filtrate, enrich with saturated $\mathrm{n}-\mathrm{Bu} \mathrm{OH}$, and mix thoroughly. Retain the butanol, condense and use for chromatography. Separate the saponins using chloroform, glacial acetic acid, methanol and water (64:34:12:8) solvent mixture. Expose the chromatogram to the iodine vapors. The colour (yellow) and hRf values of these spots were recorded by exposing chromatogram to the iodine vapours [10].

\section{Test for Steroid}

TLC method Extract two grams of powdered test samples with $10 \mathrm{ml}$ methanol in water bath $\left(80^{\circ} \mathrm{C} / 15\right.$ $\mathrm{min})$. Use the condensed filtrate for chromatography.

The sterols can be separated using chloroform, glacial acetic acid, methanol and water (64:34:12:8) solvent mixture. The color and hRf values of these spots can be recorded under visible light after spraying the plates with anisaldehyde- sulphuric acid reagent and heating $\left(100^{\circ} \mathrm{C} / 6 \mathrm{~min}\right)$ The color (Greenish black to Pinkish black) and hRf values of these spots can be recorded under visible light [10].

\section{Test for Tannin}

Braemer's test $10 \%$ alcoholic ferric chloride will be added to $2-3 \mathrm{ml}$ of methanolic extract (1:1)Dark blue or greenish grey coloration of the solution $[11,13]$.

\section{Quantitative Method of Analysis of Caesalpinia Pulcherrima}

\section{Saponins}

About 20grams each of dried plant samples were ground and, put into a conical flask after which $100 \mathrm{ml}$ of $20 \%$ aqueous ethanol were added. The mixture was heated using a hot water bath. At about $55^{\circ} \mathrm{C}$, for 4 hour with continuous stirring, after which the mixture were filtered and the residue re-extracted with a further $200 \mathrm{ml}$ of $20 \%$ ethanol. The combined extracts were reduced to $40 \mathrm{ml}$ over a water bath at about $90^{\circ} \mathrm{C}$. The concentrate was transferred into a $250 \mathrm{ml}$ separate funnel and $20 \mathrm{ml}$ of diethyl ether were added and then shaken vigorously. The aqueous layer was recovered while the ether layer was discarded. The purification process was repeated three times. $60 \mathrm{ml}$ of n-butanol were added. The combined nbutanol extracts were washed twice with $10 \mathrm{~m} 1$ of $5 \%$ aqueous sodium chloride. The remaining solution was heated in a water bath. After evaporation, the samples were dried in the oven to a constant weight; the saponin content was calculated as percentage of the starting material.

\section{Flavonoids}

About $10 \mathrm{~g}$ of the plant sample were extracted repeatedly with $100 \mathrm{ml}$ of $80 \%$ aqueous methanol, at room temperature. The whole solution was filtered through what man filter paper No 42 . The filtrate were later transferred into a crucible and evaporated into dryness over a water bath; the dry content was weighed to a constant weigh.

\section{Tannins}

About $500 \mathrm{mg}$ of the plant sample were weighed into a $50 \mathrm{ml}$ plastic bottle. $50 \mathrm{ml}$ of distilled water was added and shaken for 1 hour on a mechanical shaker. This was filtered into a $50 \mathrm{ml}$ volumetric flask and made up to the marked level. Then, $5 \mathrm{ml}$ of the filtrate was transferred into a test tube and mixed with $2 \mathrm{ml}$ of $0.1 \mathrm{M} \mathrm{FeCl}$ in $0.1 \mathrm{M}$ 


\section{Bioequivalence \& Bioavailability International Journal}

$\mathrm{Hcl}$ and $0.008 \mathrm{M}$ potassium Ferro-cyanide. The absorbance was measured at $120 \mathrm{~nm}$ within 10 minutes. The tannins content was calculated using a standard curve of extract.

\section{Alkaloids}

Five grams of the plant sample were weighed into a $250 \mathrm{ml}$ beaker and $200 \mathrm{ml}$ of $10 \%$ acetic acid in ethanol was then be added, the reaction mixture were covered and allowed to stand for 4 hour. This was filtered and the extract will be concentrated on a water bath to onequarter of the original volume. Concentrated ammonium hydroxide was added drop-wise to the extract until the precipitation is complete. The whole solution were allowed to settle and the precipitate was collected, washed with dilute ammonium hydroxide and then filtered; the residue being the alkaloid, which was dried and weighed to a constant mass.

\section{Results}

Table 1 present a summary of the antibacterial assay of ethyl acetate extract of Caesalpinia pulcherrima leaves on test bacterial species with of loxacin as antibiotics. A total of six assays were performed. The initial concentration of the Ethyl acetate extract of the leaves of Caesalpinia pulcherrima was $100 \mathrm{mg} / \mathrm{ml}$ with $12.0 \mathrm{~mm}$ zone of inhibition and $4.0 \mathrm{~mm}$ and $6.0 \mathrm{~mm}$ zone of inhibition at concentration of $12.5 \mathrm{mg} / \mathrm{ml}$ inhibits Escherichia coli and Salmonella typhi. Staphyloccocus aureus was also found to be very susceptible to this extract with $10 \mathrm{~mm}$ zone of inhibition at $100 \mathrm{mg} / \mathrm{ml}$ and $4 \mathrm{~mm}$ at $12.5 \mathrm{mg} / \mathrm{ml}$. Bacillus substilis was found to be the least susceptible with $7 \mathrm{~mm}$ at $100 \mathrm{mg} / \mathrm{ml}$ and $3 \mathrm{~mm}$ at $25 \mathrm{mg} / \mathrm{ml}$. Pseudomonas aeruginosa and Klebsiella pneumonia was not inhibited by these extracts at any concentration used in this study.

In Table 1; the Ethyl acetate extract of the barks of Caesalpiniapulcherrima shows that, Salmonella typhi and Escherichia coli was observed to be the most susceptible organism with $15.00 \mathrm{~mm}$ and $10.00 \mathrm{~mm}$ zone of inhibition at $100 \mathrm{mg} / \mathrm{ml}$ and $4.0 \mathrm{~mm}$ and $4.00 \mathrm{~mm}$ zone of inhibition at concentration of $12.5 \mathrm{mg} / \mathrm{ml}$ and $25 \mathrm{mg} / \mathrm{ml}$ respectively. Staphylococcus aureus was found to be the least susceptible organism with $10.00 \mathrm{~mm}$ at $100 \mathrm{mg} / \mathrm{ml}$ and $4.00 \mathrm{~mm}$ at $12.5 \mathrm{mg} / \mathrm{ml}$ concentration. Bacillus substilis, Klebsiella pneumonia and Pseudomonas aeruginosa was found to be non-susceptible to the ethyl acetate extract of the bark of Caesalpiniapulcherrima with no zones of inhibition at any concentration (Figures $3 \& 4$ ) (Table 2).

\begin{tabular}{|c|c|c|c|c|}
\hline Test organisms & \multicolumn{4}{|c|}{ Inhibition Zones diameter (mm) } \\
\hline & $\begin{array}{c}\mathbf{1 0 0} \\
\mathbf{m g} / \mathbf{m l}\end{array}$ & $\begin{array}{c}\mathbf{5 0} \mathbf{m g} / \mathbf{m l} \\
\mathbf{m g} / \mathbf{m l}\end{array}$ & $\begin{array}{c}\mathbf{1 2 . 5} \\
\mathbf{m g} / \mathbf{m l}\end{array}$ \\
\hline Escherichia coli & 12 & 9 & 6 & 4 \\
\hline Bacillus subtilis & 7 & 5 & 3 & 0 \\
\hline $\begin{array}{c}\text { Pseudomonas } \\
\text { aeruginosa }\end{array}$ & 9 & 5 & 4 & 0 \\
\hline $\begin{array}{c}\text { Staphylococcus } \\
\text { aureus }\end{array}$ & 10 & 7 & 5 & 4 \\
\hline $\begin{array}{c}\text { Klebsiella } \\
\text { pneumonia }\end{array}$ & 10 & 8 & 5 & 0 \\
\hline Salmonella typhi & 12 & 10 & 8 & 6 \\
\hline
\end{tabular}

Table 1: Antibacterial activity of caesalpiniapulcherrima leaf on selected clinical organisms.

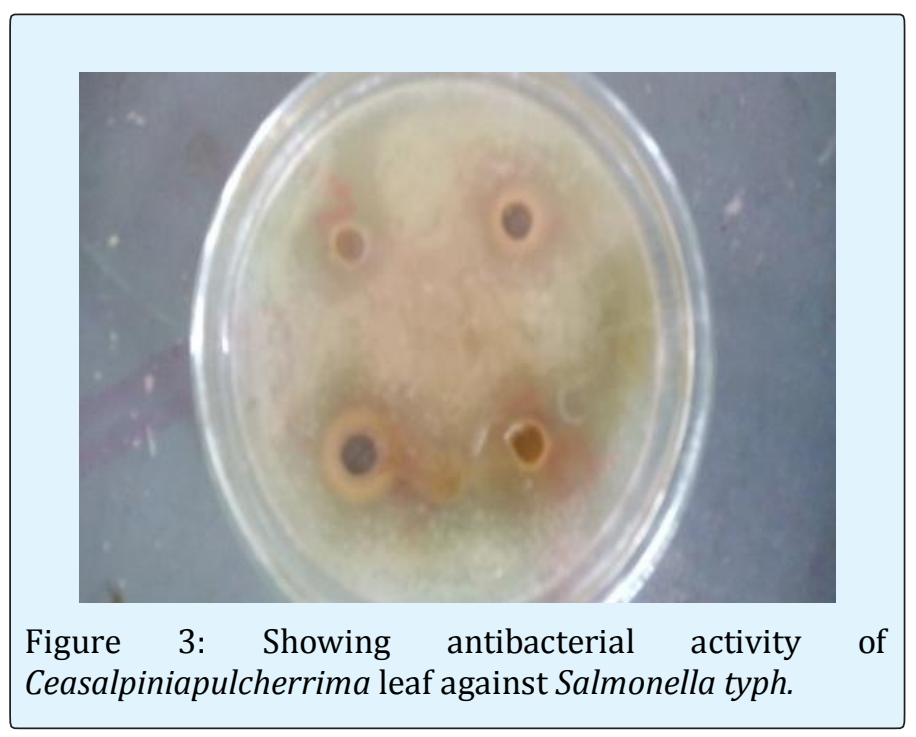

\begin{tabular}{|c|c|c|c|}
\hline \multirow[t]{2}{*}{ Test organisms } & \multicolumn{3}{|c|}{$\begin{array}{c}\text { Inhibition Zones diameter } \\
(\mathrm{mm})\end{array}$} \\
\hline & $\begin{array}{c}100 \\
\mathrm{mg} / \mathrm{ml}\end{array}$ & $\begin{array}{c}25 \\
\mathrm{mg} / \mathrm{ml}\end{array}$ & $\begin{array}{c}12.5 \\
\mathrm{mg} / \mathrm{ml}\end{array}$ \\
\hline E. coli & 12 & 4 & 3 \\
\hline Bacillus subtilis & 10 & 6 & 3 \\
\hline $\begin{array}{c}\text { Pseudomonas } \\
\text { aeruginosa }\end{array}$ & 8 & 4 & 1 \\
\hline Staphylococcus aureus & 10 & 6 & 4 \\
\hline Klebsiella pneumonia & 12 & 7 & 4 \\
\hline Salmonella typhi & 15 & 10 & 4 \\
\hline
\end{tabular}

Table 2: Antibacterial Activity of Caesalpinia Pulcherrima Stem bark On Selected Clinical Organism.
OludareTemitope Osuntokun, et al. Bioprospective Screening of Antibacterial and Phytochemical Activity of Caesalpinia Pulcherrima (Pride of Barbados) on Selected Clinical Isolate. Bioequiv \& Bioavailab Int J 2017, 1(3): 000118.
Copyright@ OludareTemitope Osuntokun, et al. 


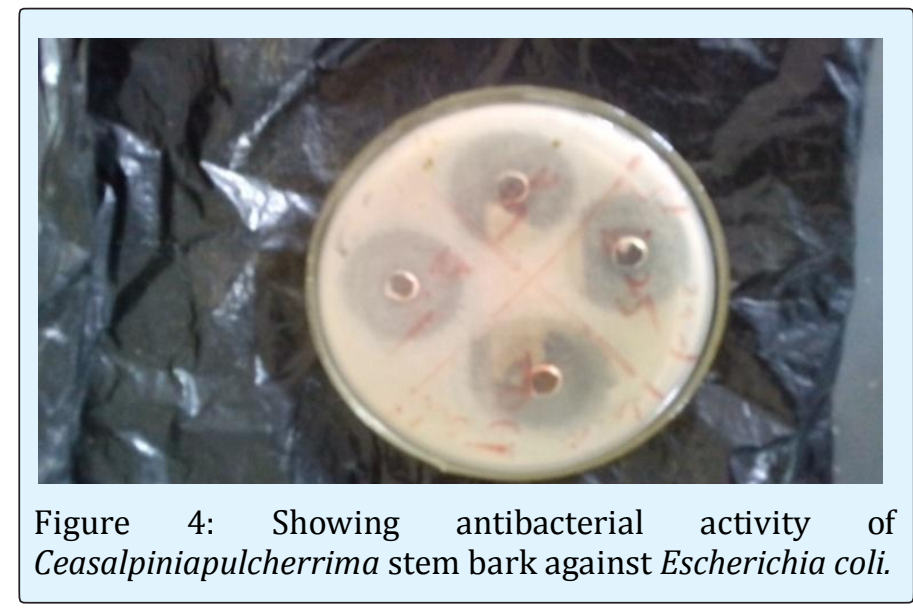

The crude methanol, ethyl acetate, N-hexane, Dichloromethane extract of the leaf and stem bark of Caesalpiniapulcherrima were qualitatively and quantitatively tested for the presence of the components, such as alkaloids, cardiac glycoside, steroids, anthraquinine, phenol, tannins, saponin, flavonoids, reducing sugars, oxalate and phytate and the results were given in Table 3 below.

Table 3, represent a summary of the qualitative phytochemical analysis of methanolic extract of Caesalpiniapulcherrima leaf and stem bark for the presence of alkaloids, cardiac glycoside, steroids, anthraquinones, phenol, tannins, saponins, flavonoids, and reducing sugar. The methanolic extract of the leaves of Caesalpiniapulcherrima possess alkaloids, anthraquinones, tannins, saponins, and reducing sugar, but doesn't possess cardiac glycoside, steroids, phenols, and flavonoids. The bark possess alkaloids, cardiac glycosides, tannins, saponins and reducing sugar, whereas the methanolic extract of the bark doesn't possess steroids, anthraquinones, phenols, and flavonoids.

In Table 4, the ethyl acetate extract of Caesalpiniapulcherrimabark possess all the phytoconstituent except for steroids where it either possess it or not. The ethyl acetate extract of the leaves of Caesalpiniapulcherrima possess cardiac glycosides, anthraquinones, phenols, tannins and saponnins but doesn't possess alkaloids, steroids, flavonoids and reducing sugar.

Table 5, shows qualitative phytochemical analysis of Dichloromethane extract of Caesalpiniapulcherrima leaf and stem bark for the presence of the 9 phytoconstituents. The leaves and stem bark possess alkaloids, steroids, phenols, saponins, flavonoids and reducing sugar. The bark doesn't contain cardiac glycosides and the leaves also do not contain anthraquinones and tannins phytoconstituents.

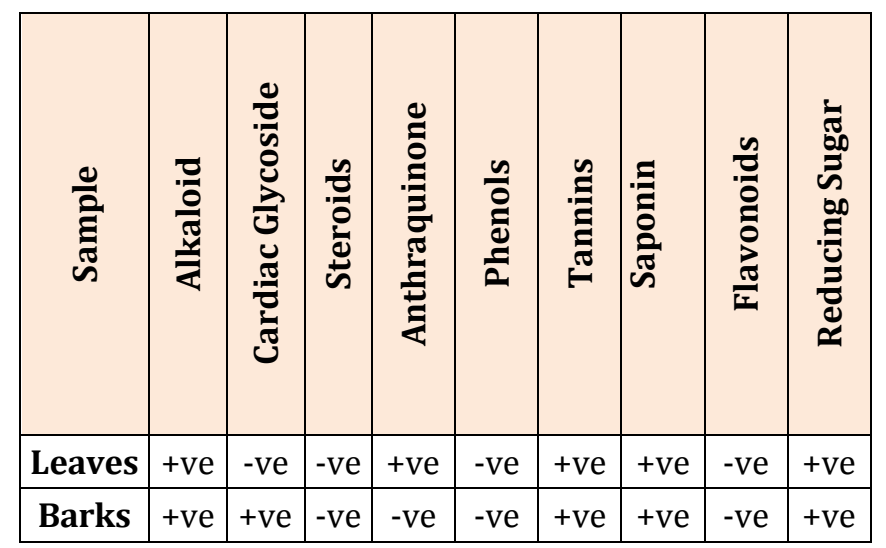

Keys: $+\mathrm{ve}=$ Presence, $-\mathrm{ve}=$ Absence, $\mathrm{ND}=$ Not $\mathrm{d}$

Table 3: Qualitative Phytochemical Analysis of Caesalpinia Pulcherima leaf And Stem Bark Extract (Methanol) \%.

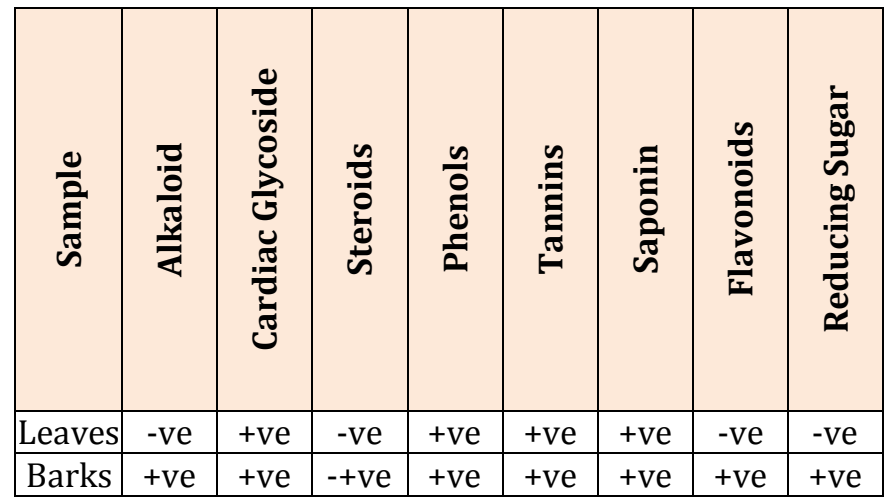

Keys: $+\mathrm{ve}=$ Presence, $-\mathrm{ve}=$ Absence, $\mathrm{ND}=$ Not detected .

Table 4: Qualitative Phytochemical Analysis of Caesalpiniapulcherrima Leaf and Stem Bark Extract (Ethyl Acetate) \%

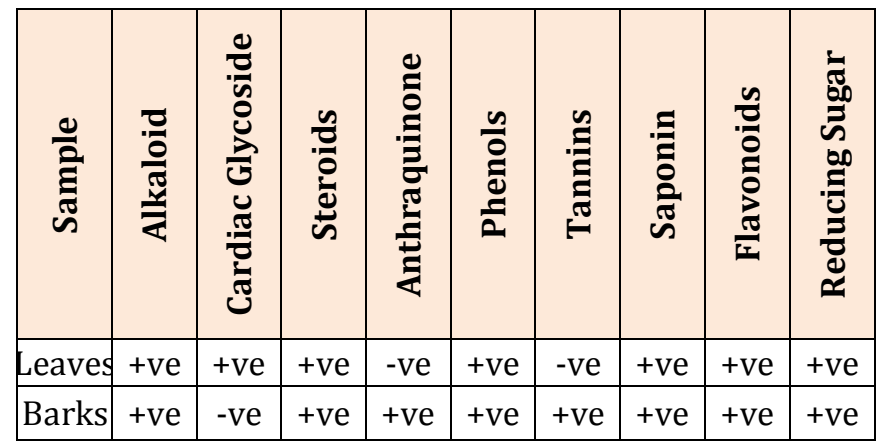

Keys: $+\mathrm{ve}=$ Presence, $-\mathrm{ve}=$ Absence, $\mathrm{ND}=$ Not detected. Table 5: Qualitative Phytochemical Analysis of Caesalpiniapulcherrima Leaf and Stem Barks Extract (Dichloro Methane) \%. 
In Table 6, the qualitative phytochemical analysis of $\mathrm{N}$ Hexane extract of the leaves of Caesalpiniapulcherrima do not possess alkaloids, steroids, flavonoids and reducing sugar but possesses cardiac glycosides, anthraquinones, phenols, tannins, and saponins. The N-Hexane extract of the stem bark of caesalpiniapulcherrima contains all the phytoconstituents except for alkaloids and reducing sugar where it either possesses it or not.

Table 7, present a summary of the quantitative phytochemical analysis of methanolic extract of Caesalpiniapulcherrima leaf and stem bark for the presence of alkaloids, oxalate, phytate, phenol, tannins, saponins, and flavonoids. The methanolic extract of the leaves of Caesalpiniapulcherrima reveals the presence of all the phytoconstituents to be in trace amount, with alkaloids and oxalate to be in lowest amount and the others to be in high amount. The phytochemicals present in the bark are all in the trace form except for flavonoids that is not detected at all.

Table 8, shows quantitative result of the plants using ethyl acetate as solvent. The leaves of Caesalpiniapulcherrima reveals the presence of alkaloids, oxalates, phytates, phenols, tannins in high amount with phytate having the highest amount as 31.49 , flavonoids in moderate amount with 7.23 and saponins in lowest amount with 5.75. Whereas, the bark depicts the presence of constituents like alkaloids, oxalate, phytate, phenol, tannins in high form with tannins being the highest of them all in quantity with 36.10 and saponin was present in moderate form while flavonoids was in trace form.

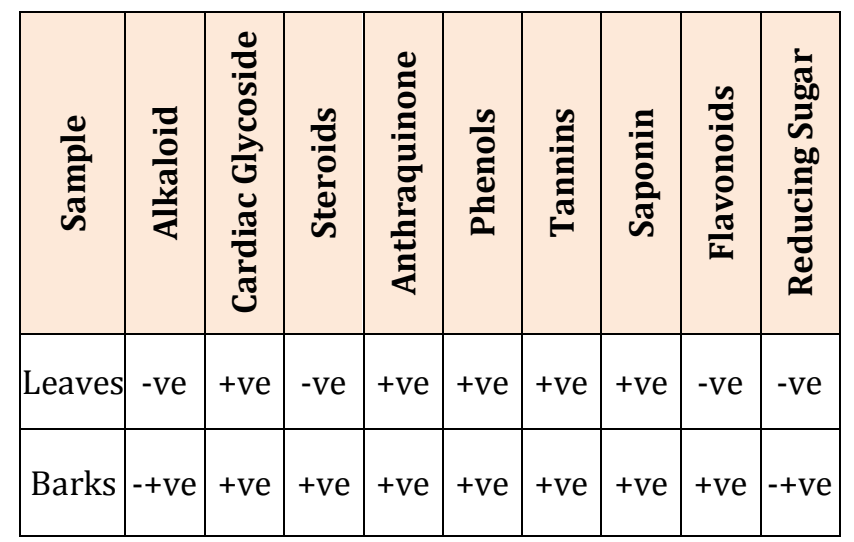

Keys: + ve $=$ Presence, - ve $=$ Absence, $\mathrm{ND}=$ Not detected

Table 6: Qualitative Phytochemical Analysis of Caesalpiniapulcherrima Leaf and Stem Barks Extract (Dichloro Methane) \%.

\begin{tabular}{|c|c|c|c|c|c|c|c|}
\hline 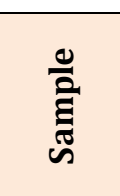 & 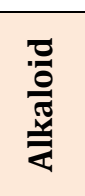 & $\begin{array}{l}\frac{\tilde{\pi}}{\pi} \\
\frac{\pi}{0}\end{array}$ & 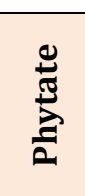 & $\begin{array}{l}\bar{d} \\
\bar{\Xi}\end{array}$ & & 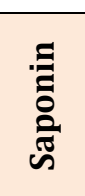 & 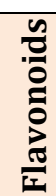 \\
\hline Leaves & 3.23 & 1.25 & 4.25 & 4.31 & 4.36 & 4.37 & 5.2 \\
\hline Barks & 2.2 & 2.1 & 2.32 & 2.37 & 2.3 & 2.25 & ND \\
\hline
\end{tabular}

Table 7: Quantitative Phytochemical Analysis of Caesalpinia Pulcherrima Leaf and Stem Bark Extract (Methanol) \%.

\begin{tabular}{|c|c|c|c|c|c|c|c|}
\hline 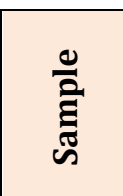 & $\begin{array}{l}\frac{\pi}{\partial} \\
\frac{0}{\pi} \\
\frac{y}{\frac{\pi}{\pi}}\end{array}$ & $\frac{\frac{\pi}{\pi}}{\pi}$ & $\sum_{\frac{\pi}{2}}^{\stackrel{D}{2}}$ & $\begin{array}{l}\bar{\Xi} \\
\bar{\Xi}\end{array}$ & & 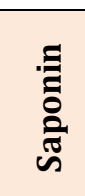 & $\begin{array}{l}\tilde{n} \\
.0 \\
0 \\
0 \\
\frac{\pi}{I}\end{array}$ \\
\hline Leaves & 20 & 26.19 & 31.49 & 22.08 & 25.07 & 5.75 & 7.23 \\
\hline Barks & 19.82 & 24.77 & 29.49 & 24.21 & 36.1 & 6.53 & 4.78 \\
\hline
\end{tabular}

Table 8: Quantitative Phytochemical Analysis of Caesalpiniapilcherrima Leaf and Stem Bark Extract (Ethyl Acetate) \%.

Table 9, reveals the quantitative phytochemical results for Caesalpiniapulcherrima leaves and stem bark using $\mathrm{N}$ Hexane as extracting solvent. It reveals the presence of alkaloids and flavonoids in moderate amount with 12.00 and 7.23 respectively and oxalate and saponins was present in trace amount with 2.19 and 5.75 respectively, whereas, phytate, phenol and tannins were present in high amount with 20.49, 22.08 and 25.07 respectively in the leaves. The bark shows that most of the phytochemicals were present in high amount, except for saponins and flavonoids which was present in small or trace amount with 6.53 and 4.78 respectively.

\begin{tabular}{|c|c|c|c|c|c|c|c|}
\hline 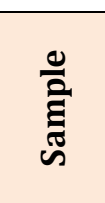 & 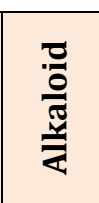 & $\begin{array}{l}\frac{\pi}{\pi} \\
\frac{\pi}{\pi} \\
0\end{array}$ & $\sum_{\frac{\pi}{2}}^{\frac{\pi}{2}}$ & $\begin{array}{l}\bar{\Xi} \\
\bar{d} \\
\bar{a}\end{array}$ & $\underset{\mathscr{E}}{\stackrel{\mathscr{E}}{\Xi}}$ & 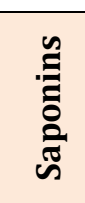 & 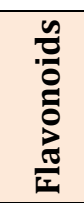 \\
\hline Leaves & 12 & 2.19 & 20.49 & 22.08 & 25.07 & 5.75 & 7.23 \\
\hline Barks & 19.82 & 14.77 & 12.49 & 20.21 & 13.1 & 6.53 & 4.78 \\
\hline
\end{tabular}

Table 9: Quantitative Phytochemical Analysis of Caesalpiniapulcherrima Leaf and Stem Bark Extract (NHexane) \%.
OludareTemitope Osuntokun, et al. Bioprospective Screening of Antibacterial and Phytochemical Activity of Caesalpinia Pulcherrima (Pride of Barbados) on Selected Clinical Isolate. Bioequiv \& Bioavailab Int J 2017, 1(3): 000118.
Copyright@ OludareTemitope Osuntokun, et al. 


\section{Bioequivalence \& Bioavailability International Journal}

\section{Discussion}

The present study carried out on the leaves and stem bark of Caesalpiniapulcherrima extracts revealed the possession of medicinal activities. Studies with reference to their specific antibacterial activity had been done to negligible extent. The screening of leaf and bark of Caesalpiniapulcherrima for antibacterial activity was carried out by agar well diffusion method. The selection of this plant is based on its use in folk medicine. In the present study, six bacterial strains were used which are responsible for various minor or major infections in humans. They are Staphylococcus aureus, Bacillussubtilis, Escherichia coli, Pseudomonas aeruginosa, Salmonella typhi and Klebsiellapneumoniae. All the extracts of leaves and stem bark of Caesalpiniapulcherrima had shown potent antibacterial activity. The extracts of leaves of Caesalpiniapulcherrima showed higher activity compared to the stem bark.

Ethyl acetate extracts of Caesalpiniapulcherrima stem bark were found to have higher inhibitory activity against Salmonella typhi, with $15 \mathrm{~mm}$ zone of inhibition at $100 \mathrm{mg} / \mathrm{ml}$ and $4 \mathrm{~mm}$ zone of inhibition at $12.5 \mathrm{mg} / \mathrm{ml}$, and Staphyloccocusaureus being the least susceptible organism, with $10 \mathrm{~mm}$ zone of inhibition at $100 \mathrm{mg} / \mathrm{ml}$ concentration and $4 \mathrm{~mm}$ zone of inhibition at $12.5 \mathrm{mg} / \mathrm{ml}$ concentration. The stem bark was also found to have high inhibitory activity to Escherichia coli, with $12 \mathrm{~mm}$ zone of inhibition at concentration of $100 \mathrm{mg} / \mathrm{ml}$ and $4 \mathrm{~mm}$ zone of inhibition at $25 \mathrm{mg} / \mathrm{ml}$. For the extract to have inhibitory activity against these test organisms, it might be due to certain bioactive compounds such as alkaloid, flavonoids and tannins present in the stem bark extract of Caesalpiniapulcherrima. This could also be as a result that the extracting solvent (ethyl acetate) used was able to extract certain bioactive compound that was active against the test organisms. Bacillus substilis, Pseudomonas aeruginosa and Klebsiella pneumonia were found not to be susceptible to ethyl acetate extract of Caesalpiniapulcherrima stem bark. This might be because the extracting solvent used was unable to extract the bioactive component necessary for the inhibition of the organisms [14].

Ethyl acetate extract of the Caesalpiniapulcherrima leaves exhibited higher inhibitory activity against all the tested organisms except Bacillus substilis and Klebsiella pneumonia, with Escherichia coli and Salmonella typhi having the highest zone of inhibition of $12 \mathrm{~mm}$ at $100 \mathrm{mg} / \mathrm{ml}, 4 \mathrm{~mm}$ and $6 \mathrm{~mm}$ zone of inhibition at $12.5 \mathrm{mg} / \mathrm{ml}$ concentration, followed by Staphyloccocusaureus, with $10 \mathrm{~mm}$ zone of inhibition at
$100 \mathrm{mg} / \mathrm{ml}$ and $4 \mathrm{~mm}$ zone of inhibition at $12.5 \mathrm{mg} / \mathrm{ml}$ concentration. Whereas, Bacillus substilis was found to be the least susceptible organism with $7 \mathrm{~mm}$ and $3 \mathrm{~mm}$ zones of inhibition at $100 \mathrm{mg} / \mathrm{ml}$ and $25 \mathrm{mg} / \mathrm{ml}$ concentrations respectively. This might be that some bioactive compounds present in the leaf extract, possess antibacterial activities against the test organisms. Bacillussubstilis and Klebsiellapneumonia that was resistant to Caesalpiniapulcherrima leaf extract could be due to the absence of compounds necessary to inhibit the growth of these organisms in the extract. The absence of these compounds might be because the solvent used in the study was unable to extract all necessary bioactive compounds from the leaf. Also concentration would have been more effective enough to inhibit the growth of all the microorganisms probably if much concentration was used [14]. It was reported that the ethyl acetate extracts of leaves of Caesalpinia Pulcherrima possess antimicrobial activity against Escherichia coli, Bacillussubtilis and Staphylococcus aureus [15]. The results of antibacterial activity of crude extracts of Caesalpiniapulcherrima were summarized in (Tables $1 \& 2$ ) respectively.

However, the crude methanol, ethyl acetate, N-hexane, Dichloro-methane was qualitatively and quantitatively tested for the presence of steroids, glycosides, alkaloids, flavonoids, anthraquinones, tannins, oxalate, phytate and phenols. The methanol, ethyl acetate and $n$-hexane extract of leaf of Caesalpiniapulcherrima does not possess steroids and flavonoids phytoconstituents. Methanol, ethyl acetate, dichloromethane \& n-hexane extracts possess tannins and saponin whereas methanol \& dichloromethane extracts possess reducing sugar. The stem bark possesses alkaloids and reducing sugar in methanol, ethyl acetate, dichloromethane, n-hexane extracts. Ethyl acetate and n-hexane extracts of the bark possess all the phytoconstituent. Whereas methanol extracts does not possess phenols and flavonoids.

Therefore, the detected different bioactive compounds in the different crude may be responsible for the antibacterial activity of plant crude extracts. It is reported that Saponins are bioactive chemical constituents which are involved in plant disease resistance because of their antimicrobial activity. Tannins are phenolic compound and their derivatives are also considered as primary antioxidants or free radical scavengers [16]. Flavonoids groups exhibited a wide range of biological activities such as antioxidant, anti-inflammatory, antimicrobial, anticancer and anti-allergic [17]. The presence of qualitative phytoconstituents was reported in (Tables 46).
OludareTemitope Osuntokun, et al. Bioprospective Screening of Antibacterial and Phytochemical Activity of Caesalpinia Pulcherrima (Pride of Barbados) on Selected Clinical Isolate. Bioequiv \& Bioavailab Int J 2017, 1(3): 000118.
Copyright@ OludareTemitope Osuntokun, et al. 
In the same way, the quantitative phytochemical analysis revealed the presence of most of the constituents tested for in different amounts. Most of the phytoconstituents were present in high quantity, some in moderate amounts and others in small or trace amount [18]. History of use of herbal medicine in the treatment of diseases can be identified with the history of medicine and with the history of civilization itself. All parts of plants were used in Ayurveda, Unani and Homeopathic systems of medicine for the treatment of various human diseases [19-24].

\section{Conclusion}

The results revealed that the crude extracts of Caesalpiniapulcherrima contain certain constituents like alkaloids, cardiac glycosides, tannins, steroids, anthraquinones, phenols, saponnins, flavonoids and reducing sugar which could make the plant useful in treating different ailments and have potential to provide useful drug for human use. The present study exhibited the antibacterial effect of various extracts of Caesalpiniapulcherrima. The inhibitory effect of the extracts justified the medicinal use of Caesalpiniapulcherrima. Hence, it is apparent that this plant has been found to possess effective antibacterial substances against a wide range of microorganisms. The plant can also be further explored for its activity against wide spectrum of microbes and can be developed into powerful antibiotics.

\section{Recommendation}

I recommend a continuous use of the Caesalpiniapulcherrima (pride of Barbados) plant, as the plant can be used against malaria, as an antiinflammatory, an anti-microbial, against staph infections, and is said to kill cancer cells. It is also an ornamental plant that can be used for decorative purposes in gardens and as houseplant.

\section{Acknowledgements}

The authors wish to express their appreciation to all the technical staffs of the laboratory unit of Both the Department of Microbiology, Faculty of Science, Adekunle Ajasin University, Akungba Akoko, Ondo State, Department of Microbiology, Faculty of Science and Department of Pharmaceutical Science (Natural product chemistry), Faculty of Pharmacy, Obafemi Awolowo University, Ile Ife, Osun State, Nigeria for their support and all the technical assistance rendered during the course of this research work.

\section{References}

1. Srinivas K, Koteswara RY, Mahender I, Das B, Krishna $\mathrm{K}$, et al. (2003) Flavonoids from Caesalpiniapulcherrima. Phytochemistry 63: 789-793.

2. Dinesh K, Jitendar S, Anupama B, Sunil K (2010) Anticonvulsant effect of the ethanol extracts of Caesalpinia pulcherrima (Linn) Sw., Fabaceae leaves. Brazilian Journal of Pharmacognosy 20(5).

3. Chiang LC, Chiang W, Liu MC, Lin CC (2003) In vitro antiviral activities of Caesalpinia pulcherrima and its related flavonoids. Journal of Antimicrobial chemotherapy 52(2): 194-198.

4. Chatterjee A, Prakashi SC (2006) The treatise in Indian Medicinal Plants. New Delhi NISCAIR.

5. Raj NK, Reddy, MS, Chaluvadi MR, Krishina DR (2001) Bioflavonoids classifications, pharmacological, biochemical effects and therapeutic potential. Indian Journal of Pharmacology 33: 2-16.

6. Pranithanchai W, Karalai C, Ponglimanant C, Subhadhirasakul S, Chantrapromma K, et al. (209) Cassanediterpenoids from the stem of Caesalpinia Pulcherrima. Phytochemistry 70: 300-304.

7. Roach JS, Mclean S, Reynolds WF, Tinton WF (2003) Cassanediterpenoids of Caesalpiniapulcherrima. J Nat Prod 66: 1378-1381.

8. Osuntokun OT, Olajubu FA (2014) Antibacterial and phytochemical properties of some Nigeria Medicinal plant on Salmonella typhi and Salmonella paratyphi isolated from infected human stool in owo local Government, Ondo State, Nigeria. Journal of Sci Research Reports 4(5).

9. Udobi CE, Onaolapo JA (2009) Phytochemical analysis and antibacterial evaluation of the leaf stem bark and root of Aftrican locusts bean (Parkiabiglobosa). J Medicinal Plants Res 3(5): 338-344.

10. Mallikharjuna PB, Rajanna LN, Seetharam YN, Sharanabasappa GK (2007) Phytochemical studies of StrychnospotatorumL.f.- A medicinal plant. E-J Chem 4(4): $510-518$.

11. Kumar GS, Jayaveera KN, Kumar CKA, Sanjay UP, Swamy BMV, et al. (2007) Antimicrobial effects of Indian medicinal plants against acne-inducing bacteria. Trop J Pharm 6(2): 717- 723.
OludareTemitope Osuntokun, et al. Bioprospective Screening of Antibacterial and Phytochemical Activity of Caesalpinia Pulcherrima (Pride of Barbados) on Selected Clinical Isolate. Bioequiv \& Bioavailab Int J 2017, 1(3): 000118.
Copyright@ OludareTemitope Osuntokun, et al. 
12. Onwukaeme DN, Ikuegbvweha TB, Asonye CC (2007) Evaluation of Phytochemicalconstituents, antibacterial activities and effect of exudate of Pycanthus Angolensis Weld Warb (Myristicaceae) on corneal ulcers in rabbits. Trop J Pharm Res 6(2): 725730.

13. Parekh J, Chanda SV (2007) In vitro antimicrobial activity and phytochemical analysis of some Indian medicinal plants. Turk J Biol 31: 53-58.

14. Chanda S, Parekh J, Karathia N (2006) Evaluation of antibacterial activity and phytochemical analysis of Bauhinia variegate L. bark. Afr J Biomed Res 9(1).

15. Pushpendra SD, Sunil NK, Sakasar, DM (2011) Antimicrobial activities of ethanolic and aqueous extracts of Caesalpiniapulcherrima flowers.International Journal of Pharmaceutical sciences and research 2(10): 2643-2646.

16. Chao PDL, Hsiu SL, Hou YC (2002) Flavonoids in herbs: Biological fates and potential interactions with xenobiotics. J Food Drug Anal 10(4): 219-228.

17. Kokate KC (1997) 4th (edn), Delhi: VallabhPrakashan. Practicalpharmacology 218.

18. Karou D, Dicko MH, Sanon S, Simpore J, Traore AS, et al. (2003) Antimarial activity of SidaacutaBurm.F. (Malvaceae) and Pterocarpuserinaceus Poir (Fabaceae). J Ethnopharmacol 89(2-3): 291-294.
19. Ayoola GA, Coker HAB, Adesegun SA, Adepoju BAA, Obaweya K, et al. (2008) Phytochemical screening and antioxidant activities of some selected medicinal plants used for malaria therapy in Southwestern Nigeria. Trop J Pharm Res 7(3): 1019-1024.

20. Li F, Li Q, Gao D, Peng Y (2009) The optimal extraction parameters and anti-diabetic activity of flavonoids from Ipomoea batatas leaf. African Journal of Traditional and Complementary and Alternative Medicine 6(2): 195-202.

21. Brittoa JD, Gracelin DHS (2011) Comparative Phytochemical screening of flowers of a few medicinal plants. International Journal of Applied Biology and Pharmaceutical Technology 2(3): 19-22.

22. Frisch JD, Frish CD (2005) Aves Brasileiras e plantas que as atraem, sao Paulo Dalgas Ecotec 398.

23. Osuntokun OT (2015) Comparative Study of Antibacterial and Phytochemical Properties of Nigerian Medicinal Plants on Salmonella bongori and Salmonella enteritidis isolated from Poultry Feaces in Owo Local Government. Ondo State, Nigeria. Archives of current research international 2(1): 1-11.

24. Phrompittayarat $\mathrm{W}$, Putalun $\mathrm{W}$, Tanaka $\mathrm{H}$, Ingkaninan $\mathrm{K}$ (2007) Comparison of various extraction methods of Bacopamonnier. Narsuan University J 15(1): 29-34.
OludareTemitope Osuntokun, et al. Bioprospective Screening of Antibacterial and Phytochemical Activity of Caesalpinia Pulcherrima (Pride of Barbados) on Selected Clinical Isolate. Bioequiv \& Bioavailab Int J 2017, 1(3): 000118.
Copyright $(\subset$ OludareTemitope Osuntokun, et al. 